\title{
Symphysis onlay bone grafting for horizontal maxillary alveolar ridge augmentation: a systematic review
}

\author{
Nermine Ramadan* \\ Department of Oral Surgery, October 6 University, 6th of October City, Egypt
}

\begin{abstract}
Purpose: To systematically review clinical studies examining the survival and success rates of implants in horizontal ridge augmentation, either prior to or in conjunction with implant placement in the anterior maxilla.

Materials and methods: A literature search was undertaken up to September 2012 including clinical studies in English with $\geq 10$ consecutively treated patients and a mean follow-up of at least 12 months. Two reviewers screened the pertinent articles and extracted the data. Key words focused on the outcome parameters (implant success, implant survival, horizontal bone gain, and intra- and postoperative complications) in studies utilizing either a simultaneous approach (ridge augmentation performed at the time of implant placement) or a staged approach (ridge augmentation performed prior to implant placement) were analyzed.

Results: A total of 10 studies met the inclusion criteria, Mean horizontal bone gain determined at reentry (implant placement) ranged from 3.4 to 5.0 mm. Intraoperative complications were not reported. Postsurgical complications included impaired sensibility in the soft tissues of the chin. The lower lip and teeth showed fewer disturbances.
\end{abstract}

Conclusions: Staged and simultaneous augmentation procedures in the anterior maxilla are both associated with high implant success and survival rates.

\section{Introduction}

Alveolar bone loss after tooth extraction is an inevitable process and can prevent favorable position and angulation of implant placement. Rehabilitation of either partially or totally edentulous patients with oral implants is nowadays the best method to restore oral aesthetic and function with predictable results. Bone volume and quality is an essential prerequisite for dental implants. Various surgical widening techniques have been described to restore ridge width. Autogenous bone grafting and ridge splitting techniques are the most commonly used.

Schropp et al. in his clinical and radiographic prospective study found out that after tooth extraction the alveolar ridge decreases in width and height rapidly, with as much as $50 \%$ loss in width during the first year, two-thirds of which occurs in the initial 3 months. Moreover when maxillary anterior and posterior teeth are lost, post extraction collapse occurs. Consequently, there is significant reduction in ridge width accompanying ridge height loss.

Many studies have shown that prerequisites for successful implants outcomes are minimum thickness of $1 \mathrm{~mm}$ to $1.5 \mathrm{~mm}$ of bone remain on both buccal and lingual/palatal aspects. Narrow edentulous alveolar ridges less than $5 \mathrm{~mm}$ wide require widening before or after implant placement to establish a bony wall of at least $1 \mathrm{~mm}$ around screw-type implants.

Autografts are for long considered the Gold standard of grafting materials and are currently the only osteogenic graft available to clinical practitioners. Grafted autogenous bone heals into the growing bone through the process of osteogenesis, osteoinduction and osteoconduction (these stages are non-separate and distinct but overlapping each other). Neiva et al. in his study showed that block size available from intraoral location has been found to be an average of $10 \mathrm{~mm}$ (height) $\times 15 \mathrm{~mm}$ (width) $\times 6 \mathrm{~mm}$ (thickness), with an average bone volume of approximately $860 \mathrm{~mm}$.

The symphysis has been reported to provide sufficient bone to augment a deficient ridge by $4-6 \mathrm{~mm}$ in the horizontal dimension, and up to $4 \mathrm{~mm}$ in the vertical dimension, covering a length of up to a 3 teeth defect. Hammack et al. concluded that cortico-cancellous nature of bone harvested from symphysis site facilitates faster vascular in-growth once the block has been placed, resulting in more rapid integration and less potential resorption during healing. However, Pikos in his experience with 434 block grafts stated that despite the many advantages block grafts offer for alveolar ridge augmentation, complications can occur when mandibular block autografts were used for horizontal and vertical augmentation. Morbidity with this grafting protocol was associated with donor and recipient sites. Infection rate was minimal $(<1 \%)$. Neurosensory deficits include altered sensation of the lower lip, chin $(<1 \%$ permanent), and dysesthesia of the anterior mandibular dentition (transient, 53\%; permanent, $<1 \%$ ).

\section{Materials and methods}

Inclusion and exclusion criteria were defined before beginning the

Correspondence to: Nermine Ramadan, Ville 86, Hayat Residence Compound, Shorouk City, Egypt, Tel: (+2) 010-63330806; E-mail: nermine.ramadan@gmail.com

Key words: maxillary alveolar ridge, grafting - bone augmentation, autogenous bone graft, chin graft

Received: November 09, 2015; Accepted: December 06, 2015; Published: December 06, 2015 
study by the authors. Criteria included study type, number of treated patients, type and area of intervention, outcome parameters and follow-up period.

\section{Study type}

Only clinical studies in humans and published in English were accepted for this systematic review. Experimental studies, case reports, review articles, technical notes, and expert opinion articles were excluded. The clinical study had to be performed in a minimum of 10 patients, irrespective of the number of treated patients for a given therapeutic option.

\section{Type and area of intervention}

Horizontal bone augmentation had to be carried out in the anterior maxilla (esthetic zone), defined as the area from the right first premolar to the left first premolar. Studies reporting vertical ridge augmentation, distraction osteogenesis, ridge expansion or splitting techniques, and alveolar socket preservation were excluded for this review. Clinical studies on horizontal bone augmentation in patients with congenital malformations, after tumor resection, or following osteoradionecrosis were also excluded, since treatment and outcome in these cases are not comparable.

\section{Outcome parameters and follow-up period}

Studies were included provided they reported data about the horizontal bone gain at reentry time or reporting intra- and postoperative complications were also included.

\section{Search strategy}

PubMed using Endnote X4 served as the source for searching studies up to 2015 Articles were selected using the following search terms (Table 1):

Inclusion criteria for the control:

- Papers written in English

- Human studies

- Horizontal alveolar ridge deficiency

- Missing maxillary anterior teeth

- Autogenous bone grafting

Exclusion criteria for the control:

- Papers written in languages other than English language

- Animal studies

- Studies on mandible

- Grafting procedures other than autogenous onlay block bone grafts (e.g. particulate).

Focus question: Does horizontal ridge augmentation using onlay

Table 1. Searching studies.

\begin{tabular}{|c|c|c|}
\hline Search number & Keywords & Articles \\
\hline$\# 1$ & Maxillary alveolar ridge & 1636 \\
\hline$\# 2$ & Grafting - Bone augmentation & 657 \\
\hline$\# 3$ & Autogenous bone graft & 579 \\
\hline$\# 4$ & Chin graft & 72 \\
\hline$\# 5$ & $\# 1 \& \# 2 \# 3 \# 4 \& \# 5$ & 19 \\
\hline
\end{tabular}

bone graft prior to implant placement in the anterior maxilla influence the implant outcome?

Systematic flow diagram:

- $\quad$ Total identified studies $=19$

- Studies excluded after titles screening $=9$

- Studies identified for abstract screening $=10$

- Studies excluded after abstracts screening $=9$

- Studies excluded after full text screening $=0$

- Included studies after full text screening $=10$

\section{Data extraction}

Data were extracted and recalculated for those sites. The following information was collected from the publications:

- Number of treated patients

- Material/technique used for horizontal ridge augmentation

- Width of alveolar bone before and after augmentation

- Intra- and postoperative complications

- Interval between augmentation and reentry

- Width of alveolar bone at reentry

- Number of inserted implants

- Follow-up period of loaded implants

- Success rate of loaded implants (with success criteria) in the augmented ridge

- Survival rate of loaded implants in the augmented ridge

\section{Results}

The literature search yielded a total of 19 publications within the specified search terms. 10 articles fulfilled the inclusion criteria for data extraction (Table 2) and 9 studies were excluded after screening the titles (Table 3).

In 2015 a study was done on bimaxillary protrusion in a 28 -yearold woman was complicated by multiple missing, restoratively compromised, or hopeless teeth. Maxillary right central incisor had a history of avulsion and replantation that subsequently evolved into generalized external root resorption with Class III mobility and severe loss of supporting periodontium. Augmentation of alveolar defect with an autogenous chin-block graft, enhancement of gingival biotype with a connective tissue graft, and an implant-supported prosthesis was done. Orthodontists must understand the limitations of bone grafts. Augmented alveolar defects are slow to completely turn over to living bone, so they are usually good sites for implants but respond poorly to orthodontic space closure. However, postsurgical orthodontic treatment is often indicated to optimally finish the esthetic zone before placing final prosthesis. The latter was effectively performed for this patient, resulting in a total treatment time of about 36 months for comprehensive interdisciplinary care. An excellent functional and esthetic result was achieved [1].

In 2012 a retrospective study was done in purpose to assess the efficacy of a block tenting technique for reconstruction of vertical or horizontal alveolar ridge defects. Patients who underwent a block tenting 
Table 2. List of included articles.

\begin{tabular}{|c|c|c|c|c|c|c|c|c|c|c|c|c|c|}
\hline & Title & Authors & $\begin{array}{l}\text { Type of } \\
\text { study }\end{array}$ & $\begin{array}{c}\text { publication } \\
\text { year }\end{array}$ & $\begin{array}{l}\text { Number } \\
\text { of } \\
\text { patients }\end{array}$ & Age & Sex & $\begin{array}{l}\text { follow } \\
\text { up }\end{array}$ & $\begin{array}{l}\text { Width } \\
\text { gain }\end{array}$ & $\begin{array}{l}\text { Graft failure/ } \\
\text { resorption }\end{array}$ & $\begin{array}{c}\text { Number } \\
\text { of } \\
\text { implants }\end{array}$ & $\begin{array}{l}\text { Failed } \\
\text { implant } \\
\text { (s) }\end{array}$ & complications \\
\hline 1 & $\begin{array}{l}\text { Bimaxillary protrusion with } \\
\text { an atrophic alveolar defect: } \\
\text { orthodontics, autogenous chin- } \\
\text { block graft, soft tissue } \\
\text { augmentation, and an implant. }\end{array}$ & $\begin{array}{l}\text { Chiu GS, Chang } \\
\text { CH, Roberts WE. }\end{array}$ & Case report & 2015 & 1 & 28 & q & $\begin{array}{c}36 \\
\text { months }\end{array}$ & & & 1 & & \\
\hline 2 & $\begin{array}{l}\text { Localized bone augmentation } \\
\text { with cortical bone blocks } \\
\text { tented over different } \\
\text { particulate bone substitutes: a } \\
\text { retrospective study. }\end{array}$ & $\begin{array}{l}\text { Khojasteh } \\
\text { A, Behnia } \\
\text { H, Shayesteh } \\
\text { YS, Morad } \\
\text { G, Alikhasi M. }\end{array}$ & retrospective & 2012 & 102 & $\begin{array}{c}20-73 \\
\text { Mean } \\
52.4\end{array}$ & & $\begin{array}{c}11-38 \\
\text { months }\end{array}$ & $\begin{array}{c}4.31+- \\
0.93\end{array}$ & $\begin{array}{l}\text { Failures in } 13 \\
\text { Ptients mainly } \\
\text { associate with } \\
\text { allogenic blocks }\end{array}$ & 237 & 5 & \\
\hline 3 & $\begin{array}{l}\text { Implant survival in maxillary and } \\
\text { mandibular osseous onlay grafts } \\
\text { and native bone: a 3-year clinical } \\
\text { and computerized tomographic } \\
\text { follow-up. }\end{array}$ & $\begin{array}{l}\text { Sbordone L, Toti } \\
\text { P, Menchini- } \\
\text { FabrisG, Sbordone } \\
\text { C, Guidetti F. }\end{array}$ & retrospective & 2009 & 40 & & & 3years & & $\begin{array}{c}\text { Resorption } \\
4.6+/-0.9 \\
\text { buccally } \\
3.8+/-0.8 \mathrm{~mm} \\
\text { palatally }\end{array}$ & 197 & & \\
\hline 4 & $\begin{array}{l}\text { Volume changes } \\
\text { of autogenous bone grafts } \\
\text { after alveolar ridge augmentation } \\
\text { of atrophic maxillae and mandibles. }\end{array}$ & $\begin{array}{l}\text { Sbordone L, Toti } \\
\text { P, Menchini- } \\
\text { Fabris } \\
\text { GB, Sbordone } \\
\text { C, Piombino } \\
\text { P, Guidetti F. }\end{array}$ & retrospective & 2009 & 14 & & & 1year & & $\begin{array}{l}\text { mean volume } \\
\text { resorption of } \\
35-51 \%\end{array}$ & & & \\
\hline 5 & $\begin{array}{l}\text { Morbidity } \\
\text { after chin bone harvesting--a } \\
\text { retrospective long-term follow-up } \\
\text { study. }\end{array}$ & $\begin{array}{l}\text { Weibull } \\
\text { L, Widmark } \\
\text { G, Ivanoff } \\
\text { CJ, Borg } \\
\text { E, Rasmusson L. }\end{array}$ & Clinical trial & 2009 & 60 & $\begin{array}{c}23-81 \\
\text { Mean } \\
49\end{array}$ & $\begin{array}{l}18 \text { क } \\
28 \hat{0}\end{array}$ & $\begin{array}{c}7.5 \\
\text { years }\end{array}$ & $\begin{array}{c}\text { Width } \\
10-20 \\
\mathrm{~mm}\end{array}$ & & & & $\begin{array}{c}\text { impaired } \\
\text { sensibility in } \\
\text { the soft tissues } \\
\text { of the chin. } \\
\text { The lower } \\
\text { lip and teeth } \\
\text { showed fewer } \\
\text { disturbances. }\end{array}$ \\
\hline 6 & $\begin{array}{l}\text { Microscopic analysis of } \\
\text { reconstructed maxillary alveolar ridges } \\
\text { using autogenous bone grafts from } \\
\text { the chin and iliac crest. }\end{array}$ & $\begin{array}{l}\text { Matsumoto } \\
\text { MA, Filho } \\
\text { HN, Francischone } \\
\text { aE, Consolaro A. }\end{array}$ & Clinical trial & 2005 & 10 & $\begin{array}{c}28-67 \\
\text { Mean } \\
47\end{array}$ & $\begin{array}{l}5 \text { ㅇ } \\
5 \hat{0}\end{array}$ & & & & & & \\
\hline 7 & Morbidity of chin bone harvesting. & $\begin{array}{l}\text { Raghoebar } \\
\text { GM, Louwerse } \\
\text { C, Kalk } \\
\text { WW, Vissink A. }\end{array}$ & Clinical trial & 2001 & & & & & & & & & $\begin{array}{l}\text { reported a } \\
\text { changed } \\
\text { (decreased) } \\
\text { sensibility in } \\
\text { the harvesting } \\
\text { area. }\end{array}$ \\
\hline 8 & $\begin{array}{l}\text { Autogenous mandibular bone grafts } \\
\text { in the treatment of the } \\
\text { resorbed maxillary anterior alveolar } \\
\text { ridge: rationale and approach. }\end{array}$ & $\begin{array}{l}\text { Garg AK, Morales } \\
\text { MJ, Navarro } \\
\text { I, Duarte F. }\end{array}$ & Clinical trial & 1998 & & & & & & & & & \\
\hline 9 & $\begin{array}{l}\text { Autogenous onlay bone grafts } \\
\text { fixed with screw implants for the } \\
\text { treatment of severely resorbed } \\
\text { maxillae. Radiographic evaluation } \\
\text { of preoperative bone dimensions, } \\
\text { postoperative bone loss, and } \\
\text { changes in soft-tissue profile. }\end{array}$ & $\begin{array}{l}\text { Nyström } \\
\text { E, Ahlqvist } \\
\text { J, Kahnberg } \\
\text { KE, Rosenquist } \\
\text { JB. }\end{array}$ & Clinical trial & 1996 & 30 & & & 3years & & & 156 & & $\begin{array}{l}\text { mean loss of } \\
4.9 \mathrm{~mm} \text { after } 3 \\
\text { years }\end{array}$ \\
\hline 10 & $\begin{array}{l}\text { Small-segment symphysis graft: } \\
\text { augmentation of } \\
\text { the maxillary anterior ridge }\end{array}$ & Smiler DG. & Clinical trial & 1996 & & & & & & & & & \\
\hline
\end{tabular}

graft technique between 2005 and 2010 were analyzed retrospectively. Intraoral bone blocks (ramus, chin, or tuberosity) or allogeneic blocks were fixed at $4 \mathrm{~mm}$ from deficient area, and gap was filled with bone substitutes, with or without plasma rich in growth factors. Implants were placed simultaneously or 4 to 5 months postgrafting. Patient demographic information, amount of width/height augmentation after 4 to 5 months of healing, complications, and contributing factors were gathered and analyzed. One hundred two patients were enrolled. Among the horizontal augmentations, the greatest width increase was achieved in maxillary anterior region $(4.31 \pm 0.93 \mathrm{~mm})$. The average height increase in the vertically augmented regions was greatest in posterior maxilla $(5.75 \pm 2.22 \mathrm{~mm})$. Mean horizontal augmentation was greatest with ramus $(3.65 \pm 0.65 \mathrm{~mm})$ and allogeneic materials $(3.97$ $\pm 0.79 \mathrm{~mm})$. The greatest vertical gain was achieved with tuberosity blocks $(4.25 \pm 3.06 \mathrm{~mm})$ and a combination of allogeneic/autogenous bone particles $(3.90 \pm 1.05 \mathrm{~mm})$. Application of PRGF showed no appreciable effect. The most common primary complications of surgery were hematoma and inflammation. The most common complication in the anterior maxilla was hematoma. Inflammation was the most common complication associated with ramus grafts, while hematoma 
Table 3. List of excluded articles.

\begin{tabular}{|c|c|c|c|}
\hline & Study & Reason for exclusion & Source \\
\hline 1 & $\begin{array}{l}\text { Reconstruction of severely resorbed alveolar ridge crests with dental implants using a bovine bone mineral for } \\
\text { augmentation. }\end{array}$ & $\begin{array}{l}\text { The use of bovine bone mineral } \\
\text { (Bio-Oss) }\end{array}$ & Int J Oral Maxillofac Implants. \\
\hline 2 & Applications of coronoid process as a bone graft in maxillofacial surgery. & The use of coronoid process & J Craniofac Surg. \\
\hline 3 & $\begin{array}{l}\text { Combined bony closure of oroantral fistula and sinus lift with mandibular bone grafts for subsequent dental } \\
\text { implant placement. }\end{array}$ & Sites: posterior region & J Oral Maxillofac Surg. \\
\hline 4 & Volume changes of grafted autogenous bone in sinus augmentation procedure. & Site: maxillary sinus & $\begin{array}{l}\text { Oral Surg Oral Med Oral Pathol } \\
\text { Oral Radiol Endod. }\end{array}$ \\
\hline 5 & $\begin{array}{l}\text { Apical and marginal bone alterations around implants in maxillary sinus augmentation grafted } \\
\text { with autogenousbone or bovine bone material and simultaneous or delayed dental implant positioning. }\end{array}$ & Site: maxillary sinus & Clin Oral Implants Res. \\
\hline 6 & $\begin{array}{l}\text { Implant success in sinus-lifted maxillae and native bone: a 3-year clinical and computerized tomographic } \\
\text { follow-up. }\end{array}$ & Site: maxillary sinus & Int J Oral Maxillofac Implants \\
\hline 7 & $\begin{array}{l}\text { Long-term changes in graft height after maxillary sinus floor elevation with different grafting materials: } \\
\text { radiographic evaluation with a minimum follow-up of } 4.5 \text { years. }\end{array}$ & Site: maxillary sinus & Clin Oral Implants Res. \\
\hline 8 & $\begin{array}{l}\text { Maxillary sinus floor augmentation using a beta-tricalcium phosphate (Cerasorb) alone compared } \\
\text { to autogenousbone grafts. }\end{array}$ & Site: maxillary sinus & Int J Oral Maxillofac Implants \\
\hline 9 & Use of endosseous implants for dental reconstruction of patients with grafted alveolar clefts. & Cleft lip and palate & J Oral Maxillofac Surg. \\
\hline
\end{tabular}

occurred most often in cases with chin and tuberosity grafts. Total graft failure occurred in 13 patients, mainly associated with the allogeneic blocks. Most patients were followed for 11 to 38 months. Five of 237 inserted implants failed to osseointegrate [2].

In 2009, a 3-year retrospective survey of implant clinical survival and computerized tomographic analysis of boneremodeling in atrophic alveolar crests reconstructed via various autogenous bone grafting procedures and in similar regions of native bone. The retrospective chart review included consecutive edentulous patients with severe alveolar crest atrophy treated between 2000 and 2002 with onlay autogenous bone grafts in the mandible and anterior maxilla (as needed) and implant insertion. Implant recipients were followed for 3 years. Defective areas were reconstructed by bone graft harvested from the chin or iliac crest. Implants in reconstructed areas were divided into two groups according to graft source. Implants in corresponding native areas served as controls. Cumulative survival rate (CSR), survival rate, and confidence interval (CI) were calculated, and linear measurements of bone remodeling around implants were assessed on computerized tomographic scans. Results were compared for statistically significant differences by Wilcoxon signed-rank test with a significance level $\mathrm{a}=0.5$.

Forty patients were treated with 109 screw-type, root-form, roughsurfaced implants inserted in 48 onlay grafts; 88 implants were placed in native bone. The implant 3-year CSRs were $98.9 \%$ (CI $96.7 \%$ to $100 \%$ ) in native bone and $99.1 \%$ (CI $97.3 \%$ to $100 \%$ ) in onlay grafts, irrespective of bone source. Mean resorption in the maxilla was $4.6 \pm$ $0.9 \mathrm{~mm}$ buccally and $3.8 \pm 0.8 \mathrm{~mm}$ palatally in areas reconstructed with chin grafts, $3.4 \pm 1.7 \mathrm{~mm}$ buccally and $2.6 \pm 1.4 \mathrm{~mm}$ palatally in areas reconstructed with iliac crest grafts, and $3.2 \pm 1.2 \mathrm{~mm}$ buccally and 2.1 $\pm 0.9 \mathrm{~mm}$ palatally in native areas. In conclusion implants that were positioned in either reconstructed or native bone represent a reliable method for rehabilitating edentulous alveolar ridges [3].

In 2009, retrospective chart review was to determine the relationship between non-vascularized osseous graft remodeling and the three-dimensional (3D) features of grafts and recipient sites, the anatomical recipient regions and different graft sources. 32 iliac crest or chin grafts were onlay-positioned in the mandible or maxilla of 14 patients. CT scans, taken before implant positioning and after 1 year, revealed a mean volume resorptidfffon of $35-51 \%$. For iliac crest grafts, the average resorption was $42 \%$ when the onlay was positioned in the anterior maxilla and 59\% when it was positioned in the posterior mandible. Spearman correlation and 3D interpolation analysis revealed, for both iliac crest groups, a moderate or advanced remodeling pattern depending on 3D features, namely graft thickness and shape, basal bone volume of recipient site, and the basalbone/graft volume ratio of the recipient site. No statistically significant differences were found between the recipient and donor site groups. Retrospective analysis of the data indicates that iliac crest grafts, onlay-positioned on adequate basal bone volume, may register a reduced volume remodeling when shaped thick in the anterior maxilla or rounded and convex, on the external surface, in the posterior mandible [4].

In 2009, study was done to assess chin graft morbidity. Resorption of the alveolar bone after tooth extraction may result in insufficient bone volume for implant placement. Augmentation of the resorbed site using autogenous bone grafts harvested from the maxillofacial region, for example, the chin, is a common method; however, it also involves donor site morbidity. Chin graft morbidity involves impaired sensibility in the frontal teeth, the gingival, and skin postoperatively. A group of 60 patients with partial edentulism in the maxilla and insufficient bone volume for implant therapy were augmented with bone grafts from the mandibular symphysis. The grafting procedure was performed between 1991 and 2001 with a follow-up period of 1 year after surgery. Postoperative sensibility of the lip, teeth, and gingiva was registered. Forty-six patients (18 women and 28 men) also participated in a long-term follow-up study. The mean age was 49 years (range 23-81 years) and the mean follow-up time was 7.5 years (range 4-14 years). The donor site was evaluated in four parts: a standardized clinical examination, radiographic examination and measurements, a mail-in questionnaire, and a survey of the medical records regarding complications and graft size. In the donor site, both hard tissue (mandibular symphysis and teeth) and soft tissue (i.e. lower lip, infralabial area, and chin) were evaluated. A questionnaire was also answered by 38 of 46 patients. In long-term follow-up, impaired tactility and sensitivity of soft tissues were registered in $7.6 \%$. Adjacent teeth (incisors, canines, first and second premolar) $(\mathrm{n}=418)$, showed increased lamina dura in seven cases $(1.7 \%)$ and four teeth had apical pathology (1.0\%). The donor site $(\mathrm{n}=45)$ showed good remineralization in 42 patients $(93.3 \%)$, and 28 patients $(62.2 \%)$ had a noticeable concavity radiologically. The questionnaires from 38 patients (answer frequency $82.3 \%$ ) rated high satisfaction with the grafting and implant treatment. This study indicates that long-term follow-up of chin graft donor site shows some postoperative morbidity. The most frequent disturbance was impaired sensibility in soft tissues of chin. Lower lip and teeth showed fewer disturbances. The rate of subjective symptoms 
was higher than the clinical findings but did, in general, not affect the patient in daily life. At radiographic examination, bone healing after chin graft harvesting did not regenerate to preoperative level. The donor site showed good remineralization but left a radiologic concavity in the majority of cases [5].

In 2005, histologically analysis of bone repair in maxillary areas reconstructed with autogenous bone grafts using 2 different donor sites, the ilium and the chin. Specimens were retrieved with trephine burs positioned transversely in augmented ridges 4 months after placement of the grafts. To analyze bone conditions, a histomorphometric study of ground sections was performed using a special template to identify 3 specific regions of the specimens: cortical bone, cancellous bone, and the region of transition between the alveolar ridge and the graft. Ten patients, 5 men and 5 women, with a mean age of 47 years (range 28 to 67) were evaluated.

Results indicated good incorporation of the grafts in this period, demonstrated by intense osteogenesis indicating an active remodeling process. In both groups, the improvement in bone quality of the receptor site was evident, independent of size of reconstruction, although chin grafts presented better bone quality. From this study it was possible to conclude that a period of 4 months is sufficient for the placement of osseointegrated implants in reconstructed areas, where chin or iliac autogenous grafts have been used [6].

In 2001, Raghoebar et al report a study on Morbidity of chin bone harvesting, they found that, the chin is a very common donor site for autogenous bone grafts. The aim of this retrospective study was to evaluate long-term morbidity of the donor site following chin bone graft harvesting. One to three years after grafting of local bone defects of the anterior maxilla with chin bone, 21 patients were recalled for objective assessment of any residual morbidity at the harvesting area. Morbidity as well as satisfaction of the patients was evaluated by a survey of the medical record, a mail-in questionnaire, and a standardized physical examination. The outcome of this study showed that there was good acceptance of chin bone harvesting procedure. The objective morbidity was low, but subjectively almost half of patients reported a changed (decreased) sensibility in harvesting area. This subjective change in sensibility did not result in noteworthy complaints or discomfort by patients, however. Although bone harvesting from chin is generally considered as a good option for reconstruction of local bony defects, the patients should be informed about the potential hazard of a changed sensibility in chin region [7].

Patients can present with a variety of conditions that limit, or prevent, the ideal placement of endosteal implants. One of these situations is depicted by an insufficient amount of bone for implant placement in the maxillary anterior alveolar ridge. Autogenous bone grafting can be used to augment ridge to provide a sufficient amount of bone for implant placement. Using the mandibular symphysis as a donor site offers ease of access, good bonequality for localized repair, a corticocancellous block graft morphology, low morbidity, and minimal graft resorption. A procedure for harvesting and placing an autogenous mandibular bone graft is presented; as are the advantages of using this location as a donor site compared with other locations [8].

In 1996, Nystroom et al make a study on thirty patients with severely resorbed edentulous maxillae underwent combined treatment of iliac bone onlay graft and titanium implants. The patients were followed for 3 years. They were radiographically examined before surgery to evaluate the bone volume at the intended implant sites. Only 13/156 implant sites were suitable for implant insertion. The bone level at implant surfaces was evaluated after 6 months and 1, 2, and 3 years, respectively. There was a continuing decrease of bone level throughout the follow-up period with a mean loss of $4.9 \mathrm{~mm}$ after 3 years and with no difference between sexes. Twenty-six implants were radiographically examined before removal, and only three of these implant sites showed radiographic signs of failure. The soft-tissue profile was analyzed cephalometrically by subtraction technique. The upper lip generally moved inward and the apex of nose and columella downward and inward. The anterior facial height increased in most of patients, resulting in a downward and inward change of lower lip, mentolabial sulcus, soft-tissue pogonion, and soft-tissue gnathion [9].

The loss of a tooth results in loss of alveolar bone, required for the placement and retention of implants. Bone can be replaced by various augmentation modalities, including a small-segment symphysis graft. The selection of the donor site, the preparation of the recipient and donor sites, the procedures of graft placement, and the closure of the donor site are presented and described. The corticotrabecular graft is obtained with a trephine drill from the mandibular symphysis and grafted to a recipient site that has been prepared with ridgeexpanding osteotomes. The graft is then mortised with a combination of an alloplast, freeze-dried demineralized bone, and autogenous bone harvested from the symphysis donor site. The learning objective of this article is to describe the procedures of a small-segment symphysis graft, using a clinical case to illustrate the text. After graft healing and lost bone regeneration, implants can be placed [10].

\section{Discussion}

Bone deficiency in the anterior maxilla prevents primary implant stability or results in an inadequate implant position with compromised esthetics or function [1]. Therefore, horizontal ridge augmentation is a prerequisite before or during implant placement. The present systematic review evaluated clinical studies reporting data about implant success, implant survival, gain of bone width, and intraand postoperative complications, in conjunction with horizontal bone augmentation limited to the anterior maxilla. The decision to focus the systematic review on the esthetic zone was based on three facts: The anterior maxilla is the most challenging area regarding esthetics in implant dentistry. Many, if not most, cases in the anterior maxilla require horizontal ridge augmentation due to partial or complete loss of the facial bone plate following tooth extraction or tooth loss. To the knowledge of the authors, no such systematic review has been carried out before. However, limiting the search to the anterior maxilla resulted in a low number of relevant clinical studies fulfilling the inclusion criteria. Additionally, in order to attain some homogeneity of included articles, the surgical approach used to improve alveolar ridge width was narrowed down to horizontal bone augmentation, thus excluding other surgical techniques like immediate implant placement with socket grafting or implant placement after ridge expansion, ridge splitting, or distraction osteogenesis. Also, the majority of excluded clinical studies could not be taken into consideration because they either report single cases, describe technical notes of alveolar ridge reconstruction, or the study material comprised maxillary and mandibular anterior and posterior cases with pooled data, thus not allowing for data extraction. Since timing, surgical technique, and geometry of defects differ in simultaneous versus staged horizontal bone augmentation, studies were grouped accordingly and will be discussed separately.

\section{References}

1. Chiu GS, Chang CH, Roberts WE (2015) Bimaxillary protrusion with an atrophic 
alveolar defect: orthodontics, autogenous chin-block graft, soft tissue augmentation, and an implant. Am J Orthod Dentofacial Orthop 147: 97-113. [Crossref]

2. Khojasteh A, Behnia H, Shayesteh YS, Morad G, Alikhasi M (2012) Localized bone augmentation with cortical bone blocks tented over different particulate bone substitutes: a retrospective study. Int J Oral Maxillofac Implants 27: 1481-1493. [Crossref]

3. Sbordone L, Toti P, Menchini-Fabris G, Sbordone C, Guidetti F (2009) Implant survival in maxillary and mandibular osseous onlay grafts and native bone: a 3-year clinical and computerized tomographic follow-up. Int J Oral Maxillofac Implants 24: 695-703. [Crossref]

4. Sbordone L, Toti P, Menchini-Fabris GB, Sbordone C, Piombino P, et al. (2009) Volume changes of autogenous bone grafts after alveolar ridge augmentation of atrophic maxillae and mandibles. Int J Oral Maxillofac Surg 38: 1059-1065. [Crossref]

5. Weibull L, Widmark G, Ivanoff CJ, Borg E, Rasmusson L (2009) Morbidity after chin bone harvesting--a retrospective long-term follow-up study. Clin Implant Dent Relat Res 11: 149-157. [Crossref]
6. Matsumoto MA, Filho HN, Francischone AE, Consolaro A (2002) Microscopic analysis of reconstructed maxillary alveolar ridges using autogenous bone grafts from the chin and iliac crest. Int J Oral Maxillofac Implants 17: 507-516. [Crossref]

7. Raghoebar GM, Louwerse C, Kalk WW, Vissink A (2001) Morbidity of chin bone harvesting. Clin Oral Implants Res 12: 503-507. [Crossref]

8. Garg AK, Morales MJ, Navarro I, Duarte F (1998) Autogenous mandibular bone grafts in the treatment of the resorbed maxillary anterior alveolar ridge: rationale and approach. Implant Dent 7: 169-176. [Crossref]

9. Nyström E, Ahlqvist J, Kahnberg KE, Rosenquist JB (1996) Autogenous onlay bone grafts fixed with screw implants for the treatment of severely resorbed maxillae. Radiographic evaluation of preoperative bone dimensions, postoperative bone loss, and changes in soft-tissue profile. Int J Oral Maxillofac Surg 5: 351-359. [Crossref]

10. Smiler DG (1996) Small segment symphysis graft: augmentation of the maxillary anterior ridge. Pract Periodontics Aesthet Dent 8: 479-483. [Crossref]

Copyright: ( 2015 Ramadan N. This is an open-access article distributed under the terms of the Creative Commons Attribution License, which permits unrestricted use, distribution, and reproduction in any medium, provided the original author and source are credited. 